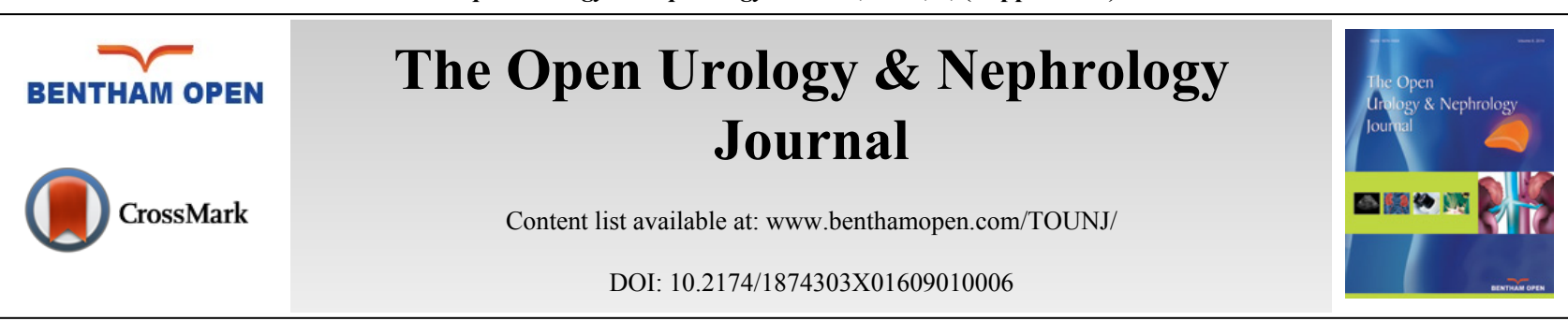

\title{
Editorial: Current Perspectives in Hyperuricemia, Gout and the Kidney
}

\author{
Vandana Dua Niyyar, MD, FASN, FNKF, FASDIN ${ }^{*} \S$ \\ Associate Professor of Medicine Division of Nephrology, Department of Internal Medicine, WMB Research Building, \\ Room 338, 1639 Pierce Drive, Emory University School of Medicine Atlanta, GA 30322
}

A myriad of factors play into the relationship between gout, hyperuricemia and kidney disease: the role of the kidney in uric acid excretion, the possible impact of hyperuricemia on progression of renal disease and in some reports, the mitigation of progression with therapeutic intervention. However, even though it is widely accepted that CKD worsens hyperuricemia, there is a lively debate on whether the reverse holds true as well. The rising prevalence of both CKD and hyperuricemia has further stimulated this interest, with the link suspected to be related to inflammatory components in both conditions. In this thematic issue, we discuss the effect of inflammasomes and the role of the innate immune system on hyperuricemia and gout, and its impact on kidney disease.

Additionally, the American College of Rheumatology recently (2012) released guidelines for the management of acute and chronic gout. In particular, the emphasis in chronic gout management is on the use of allopurinol as a firstline therapy as well as dose-titration beyond previously acceptable values, to achieve target uric acid levels below $6 \mathrm{mg} / \mathrm{dl}$. Also, given that the vast majority of patients with this painful, inflammatory arthritis are treated by primary care physicians, and there are special considerations in specific patient populations; this supplement incorporates the recom-mendations from three different perspectives: the primary care physician, the rheumatologist and the nephrologist.

(C) Vandana Dua Niyyar; Licensee Bentham Open.

This is an open access article licensed under the terms of the Creative Commons Attribution-Non-Commercial 4.0 International Public License (CC BY-NC 4.0) (https://creativecommons.org/licenses/by-nc/4.0/legalcode), which permits unrestricted, non-commercial use, distribution and reproduction in any medium, provided the work is properly cited.

\footnotetext{
* Address correspondence to this author at the Internal Medicine/ Nephrology, Emory University School of Medicine, Atlanta, GA 30322, USA; Tel: 404-727-3959; E-mail: vniyyar@emory.edu

${ }^{\S}$ Guest Editor
} 